\title{
PENGELOLAAN RUANG PUBLIK DI SEKITAR PERSIMPANGAN JALAN
}

\author{
Untung Joko Cahyono \\ Jurusan Arsitektur Fakultas Teknik Universitas Sebelas Maret \\ cahyono_u@yahoo.com
}

\begin{abstract}
Abstrak
Persimpangan jalan adalah tempat strategis yang sering memiliki conflict of interests yang sangat tinggi. Masyarakat, pemerintah/penguasa dan pengusaha dengan berbagai cara berusaha memanfaatkan tempat tersebut sesuai dengan keinginan dan persepsinya. Tulisan ini bertujuan menyoroti pemanfaatan ruang publik di sekitar persimpangan, dengan mengambil kasus beberapa persimpangan di Surakarta dan sekitarnya. Keruwetan dan kekacauan lalulintas sering terjadi, sehingga kenyamanan dan keamanan berlalu lintas sangat terganggu, terutama bagi pejalan kaki. Begitu juga secara visual, kota juga menjadi tidak indah dan tidak menyenangkan. Di persimpangan jalan selain terdapat jalur kendaraan, jalur pejalan kaki, penunjuk arah dan alat pengatur lalulintas, sering juga terdapat gardu jaga polisi/ormas, pkl, tempat istirahat, pangkalan becak/taksi, parkir, patung, monument, tugu, gapura, dan iklan outdoor. Perlu adanya penanganan yang serius mengenai ruang publik di sekitar persimpangan jalan dengan melibatkan masyarakat agar lebih memahami dan mengutamakan kenyamanan pejalan kaki dan kelancaran lalulintas serta keindahan kota. Aspek perilaku secara societal perlu diperhatikan dan di terapkan dalam pengelolaan ruang kota yang sangat penting ini.
\end{abstract}

Kata Kunci: persimpangan jalan, aksesibilitas, keindahan kota

\section{Pendahuluan}

Persimpangan jalan adalah tempat yang sangat penting dan strategis, terutama untuk lalulintas dan mobilitas masyarakat. Di persimpangan jalan orang akan berhenti, berjalan perlahan, atau paling tidak waspada dan hati-hati. Di persimpangan jalan keindahan atau kejelekan sudut-sudut kota akan terlihat.

Di Indonesia masih sangat banyak persimpangan jalan yang belum direncanakan dan disain dengan baik. Banyak pihak yang tertarik terhadap keberadaan persimpangan jalan, sehingga banyak pula konflik kepentingan di sana.

Persimpangan jalan di dalam kota membutuhkan perhatian oleh perencana, desainer/arsitek kota. Persimpangan yang didisain dengan baik akan terasa nyaman, aman dan indah. Persimpangan yang sudah didisain dengan baik pun, akan berubah menjadi buruk karena pemanfaatan ruang-ruang di sekitarnya yang tidak sesuai. Adalah sangat mendesak untuk dilakukan pengaturan dan pengelolaan ruang publik di persimpangan jalan. 


\section{Bahan dan Metode}

\subsection{Tinjauan Pustaka}

\subsubsection{Fungsi sosial-budaya, ekonomi, dan politik}

Sudut jalan adalah pertemuan jalur kendaraan dan jalur pejalan kaki, dan karena itu biasanya lebih mempunyai nilai ekonomis yang lebih tinggi daripada ruang perkotaan lainnya. Setiap persimpangan dapat menjadi tempat yang mudah dikenali dan diingat dengan baik, sehingga menjadi tempat yang penting dan strategis untuk perusahaan komersial dan fungsi sosial. Di sistem pergerakan sekunder perkotaan, sudut jalan dapat mengundang interaksi sosial yang intensif. Pada tingkat dasar seperti itu persimpangan dapat berkembang menjadi plaza atau alun-alun yang dikelilingi oleh lembaga publik atau menjadi simpul perdagangan di jantung komersial kota. (Thomas, 2002)

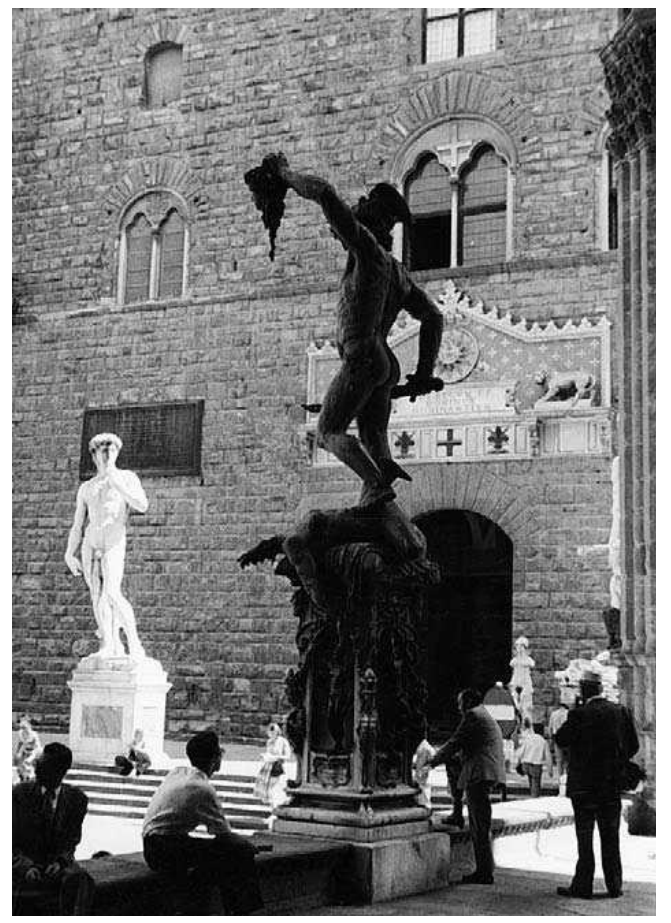

Gambar 1: Piazza Signoria, Florence, Italy Sebuah plaza yang telah berfungsi selama tujuh ratus tahun sebagai ruang publik untuk berkumpul, pertemuan, pertunjukan sircus dan tempat eksekusi. Juga terkenal sebagai tempat memamerkan karya-karya seni patung oleh seniman-seniman besar.

(Sumber: Thomas, 2002)

Kota-kota paling manusiawi selalu dipenuhi café jalanan yang menyediakan tempat bagi orang untuk berkumpul di persimpangan jalan, taman, alun-alun, di sepanjang promenade jalan. Jalan-jalan yang sibuk harus memungkinkan bagian depan café tumpah keluar ke trotoar, sehingga set meja dan kursi diletakkan sampai ke public place. Penjual makanan harus diakomodasi sehingga tempat duduk publik dapat dimanfaatkan untuk menikmati makanan kecil sambil duduk. (Alexander et.al, 1977) 


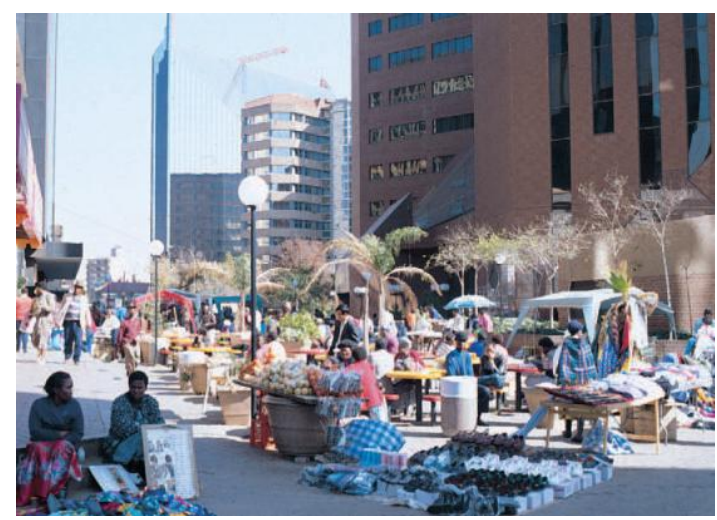

Gambar 2: Pusat Kota Johannesburg, Afrika Selatan: Perdagangan jalanan, sebuah makna dari kebebasan ekonomi untuk masyarakat urban.

(Sumber: Thomas, 2002)

Demokrasi membawa pemberdayaan dan perkembangan perdagangan informal, dan bisa sebagai pilar untuk bertahan hidup di daerah perkotaan terutama di negara-negara berkembang. Untuk menjadi peluang usaha secara komersial yang layak, hal tersebut membutuhkan ruang kota yang sesuai, seperti pada node atau simpul dari aktivitas pejalan kaki yang ramai. Revitalisasi arsitektur di kota-kota menjadi hidup dengan rangsangan visual efek kontemporer seperti pencahayaan atau spanduk berwarna-warni yang menarik perhatian masyarakat, seperti di tempattempat bersejarah atau acara-acara budaya.

Bundaran HI (Hotel Indonesia) dimana terdapat Tugu Selamat Datang di Jakarta, adalah contoh ruang public di persimpangan jalan yang bisa berfungsi dengan baik. Bundaran tersebut terletak di jantung Kota Jakarta. Yaitu merupakan pertemuan jalan utama, Jalan M.H. Thamrin yang bersinggungan dengan Jalan Imam Bonjol, Jalan Sutan Syahrir dan Jalan Kebon Kacang. Dalam penyelesaiannya, Hotel Indonesia dan bundarannya adalah sebagai pintu gerbang bagi pengunjung Kota Jakarta. Bundaran HI dengan Tugu selamat Datang dan air mancur selesai dibangun tahun 1961, dan diarsiteki Henk Ngantung dan Edhi Suna. Pada tahun 2002, Bundaran Hotel Indonesia telah direstorasi oleh PT Jaya Konstruksi Manggala Pratama. Setelah Era Reformasi, plaza dengan paving yang mengelilingi kolam menjadi popular sebagai tempat untuk berdemonstrasi. Setiap minggu pagi, saat CFD (Car-Free Days), kawasan bundaran HI dipenuhi masyarakat untuk berjoging, bersepeda, dan juga PKL.
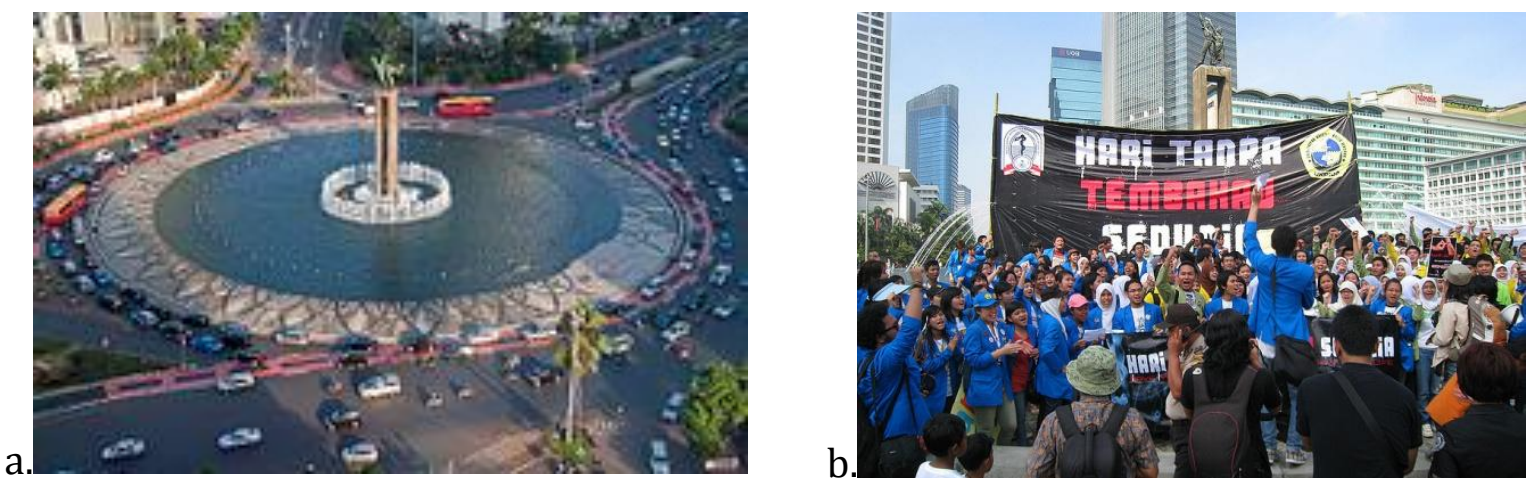

Gambar 3: a. Bundaran Hotel Indonesia, Persimpangan jalan yang sangat besar dan menjadi salah satu landmark Kota Jakarta.; b. Mahasiswa Kedokteran berdemo Anti Rokok dalam Hari Tanpa Tembakau Sedunia di Bundaran Hotel Indonesia. (Sumber: en.wikipedia.org) 


\subsubsection{Persimpangan dan sudut keindahan kota}

Area di sekitar persimpangan merupakan ruang publik yang penting dan dapat dijadikan sebagai tanda yang berfungsi untuk memperkaya kesan visual pada lingkungan dan tata ruang suatu kota. Sehingga keberadaan persimpangan sering dijadikan unsur yang penting karena berkaitan erat dengan keindahan dan penempatan ornamen-ornamen. Permasalahan yang dikwatirkan adalah apabila perancang tidak peka terhadap ruang yang akan dirancang, khususnya sudut suatu persimpangan sebagai penghubung dua elemen yang tegas dalam sebuah ruang kota yang bisa saja tidak diyakini oleh perancangnya sebagai masalah pokok desain. Para Arsitek dan Perancang kota harus merespons dengan positif bahwa sudut pada suatu persimpangan sebagai sebuah masalah desain dan hasil karya. Sehingga dalam hal ini, sudut jalan pada persimpangan harus memberikan kesempatan yang besar untuk mengenalkan ornamen-ornamen dekorasi ke dalam suatu ruang kota. (Marpaung, 2003)

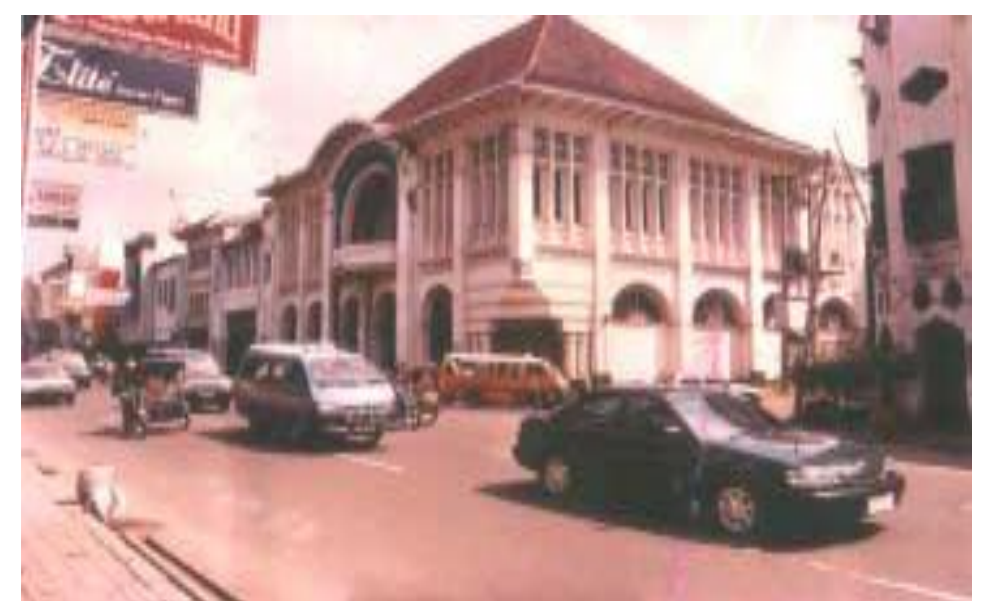

Gambar 4: Bangunan eks Bank Modern yang pada masa kolonial Belanda dirancang sebagai bangunan sudut yang keberadaanya sangat mendukung makna persimpangan yang dibentuk oleh Jalan Ahmad Yani dan Mayjend Sutoyo, Medan.

(Sumber: Marpaung, 2003)

\subsubsection{Fungsi lalu-lintas}

Konsep-konsep dasar perencanaan persimpangan jalan yang baik adalah bahwa persimpangan dapat mengalirkan aliran lalu lintas dengan baik dari satu jalan ke jalan lainnya dan membiarkan pergerakan pada jalan utama (major/primer) tidak terganggu. Untuk melakukan hal ini, bagan dan operasi persimpangan itu harus terang dan jelas dengan pandangan yang baik di antara pergerakan-pergerakan yang ada. (Ma'soem, 2007) Beberapa persyaratan teknis persimpangan yang baik meliputi halhal sebagai berikut.

a. Geometri Persimpangan Jalan. Radius berputar yang disediakan cukup memadai untuk kendaraan sehingga roda ban tidak menghantam kerb; tidak ada halangan pohon-pohon dekat pada garis tepi; pendekat pada persimpangan dilengkapi dengan lajur ruang simpan yang cukup untuk dipakai berbelok kendaraan-kendaraan; lajur pejalan kaki mempunyai desain yang tepat untuk kenyamanan pejalan kaki dan layanan khusus untuk orang-orang tidak mampu jalan. 
b. Pulau Jalan. Pembuatan pulau di persimpangan jalan dapat mengurangi perilaku pengemudi yang jelek seperti pemotongan sudut dan penutupan lajur; menghindari ketidakpastian pengemudi untuk mengambil keputusan pada aliran lalu lintas; pulau jalan cukup ruang untuk tempat berhentinya pejalan kaki ketika menyeberang jalan dan aksesibel untuk orang-orang cacat; tidak ada penghalang visual di pulau jalan, seperti pohon dan taman.

c. Rambu Jalan. Penempatan rambu jalan bisa dilihat dengan baik dan tidak terhalang ranting pohon; tidak ada papan reklame dan objek lain di tepi jalan raya yang menggangu sehingga membingungkan para pengemudi;

d. Marka Jalan. Diperlukan marka yang benar terutama pada persimpangan yang lebar/luas; perlu disediakan marka jalan pada pendekat henti dan pendekat give way, seperti juga marka tengah dan tepi jalan.

e. Lampu Lalu Lintas. Lampu lalu lintas ditempatkan dengan baik, sehingga bisa dilihat dengan jelas oleh para pengemudi; fase lampu hijau disesuaikan dengan jumlah kendaraan; perlu disediakan lampu untuk pejalan kaki.

f. Jarak Pandang (bebas halangan visual/tembus pandang). Jarak pandang pada persimpangan jalan dari jalan minor memiliki jarak pandang yang baik untuk berbelok, sehingga pengemudi itu berada di dalam situasi yang aman dari kendaraan lain atau pejalan kaki.

g. Drainase. Permukaan perkerasan pada persimpangan mempunyai kelandaian yang

standar, untuk mengalir ke dalam parit drainase. Perlu pemeliharaan yang cukup sehingga parit-parit itu dapat mengalirkan air jalan.

\subsubsection{Pengelolaan berbasis masyarakat}

Pada umumnya alat untuk mengontrol desain urban adalah "design review". Sebagai sebuag alat control secara menyeluruh, desain review membantu dalam mengatur bagian-bagian dari lingkungan yang dibangun secara visual, karakter, dan fungsional sesuai dengan nilai-nilai dan tujuan dari "community of interests", seperti kenyamanan pejalan kaki dan keindahan bangunan. (Shirvani, 1981)

Banyak keuntungan yang didapatkan dari proses Urban design Review, diantaranya adalah meningkatkan peluang pembangunan ekonomi, memastikan arus lalu lintas yang aman, harmonis arsitektur antara bangunan dan lansekap, menempatkan utilitas bawah tanah, mengurangi tanda dan kekacauan visual. (Mylroie, 1976, dalam Shirvani, 1981)

Adipura adalah salah satu bentuk "design review" yang diterapkan di Indonesia. Adipura, adalah sebuah penghargaan bagi kota di Indonesia yang berhasil dalam kebersihan serta pengelolaan lingkungan perkotaan. Adipura diselenggarakan oleh Kementerian Negara Lingkungan Hidup. Program Adipura telah dilaksanakan setiap tahun sejak 1986, sempat terhenti pada tahun 1998, kemudian kembali dicanangkan di Denpasar, Bali pada tanggal 5 Juni 2002, dan berlanjut hingga sekarang. Adapun kriteria penilaian Adipura didasarkan pada 2 indikator. Indikator yang pertama adalah kondisi fisik lingkungan perkotaan dalam hal kebersihan dan keteduhan kota. Dan indikator yang kedua adalah pengelolaan lingkungan perkotaan (non-fisik), yang meliputi institusi, manajemen, dan daya tanggap.

Penilaian fisik meliputi keadaan perumahan, sarana kota (jalan arteri dan kolektor), pasar, rumah sakit, perkantoran, RTH, sarana transportasi (terminal, stasiun, pelabuhan), Sarana Kebersihan, Tempat Wisata. Penilaian sarana kota seperti 
pemantauan jalan (Jalan arteri dan jalan kolektor) meliputi badan jalan, median jalan, dan daerah milik jalan; trotoar; drainase; dan penataan PKL.

Peran persimpangan jalan adalah sangat strategis dalam penilaian keadaan fisik lingkungan kota dan pengelolaannya. Keberhasilan pengelolaan persimpangan jalan jelas membutuhkan keterlibatan masyarakat.

\subsection{Metode Penelitian}

Peninjauan teori, konsep dan preseden tentang persimpangan jalan diperoleh melalui kajian literature dari pustaka baik secara on-line maupun off-line. Lokasi penelitian adalah Daerah Surakarta, yaitu Kota Solo dan sekitarnya. Sedangkan penentuan contoh persimpangan yang diteliti berdasarkan purposive sampling, yang dikelompokkan dalam persimpangan besar dan kecil.

Kelompok persimpangan besar adalah Proliman Sukoharjo, Pendawa Solobaru, Gemblegan, Gladag, Monumen Pers, Panggung, dan Ngarsopuro. Kelompok persimpangan kecil meliputi Bundaran Baron, Sangkrah, Pasar Gede dan Singosaren. Pembahasan untuk setiap kelompok sampel berdasarkan pada pengelolaan ruang publik di persimpangan yang meliputi fungsi lalu-lintas, keindahan, social-budaya, dan ekonomi.

\section{Hasil dan Pembahasan}

\subsection{Fungsi lalu-lintas}

Hampir semua persimpangan tidak memiliki marka atau pemandu jalur kendaraan saat dipersimpangan, sehingga pengendara sering tidak tepat memposiikan kendaraan saat berbelok. Pada umumnya akses pejalan kaki masih belum diperhatikan dengan baik, diantaranya belum tersedia jalur yang menerus dan bebas penghalang. Trotoar terlalu sempit dan sering digunakan PKL. Jalur penyeberangan atau zebracross sering tidak direncanakan dengan baik dalam hal perletakannya dan bersambungnya dengan trotoar. Angkutan umum sering berhenti di persimpangan untuk menurunkan dan menunggu penumpang. Hal ini mengganggu pandangan dan menghalangi pengguna jalan yang lain. Dengan luasnya area persimpangan, sebenarnya memungkinkan dibuat pulau-pulau untuk mengatur jalur dan transit pejalan kaki seperti di persimpangan Monumen Pers. (Gambar 5) Hanya saja perlu dipikirkan untuk membuat pulau-pulau ini lebih rendah untuk akses pejalan kaki, dan tidak membuat taman/penghijauan yang menghalangi pandangan.
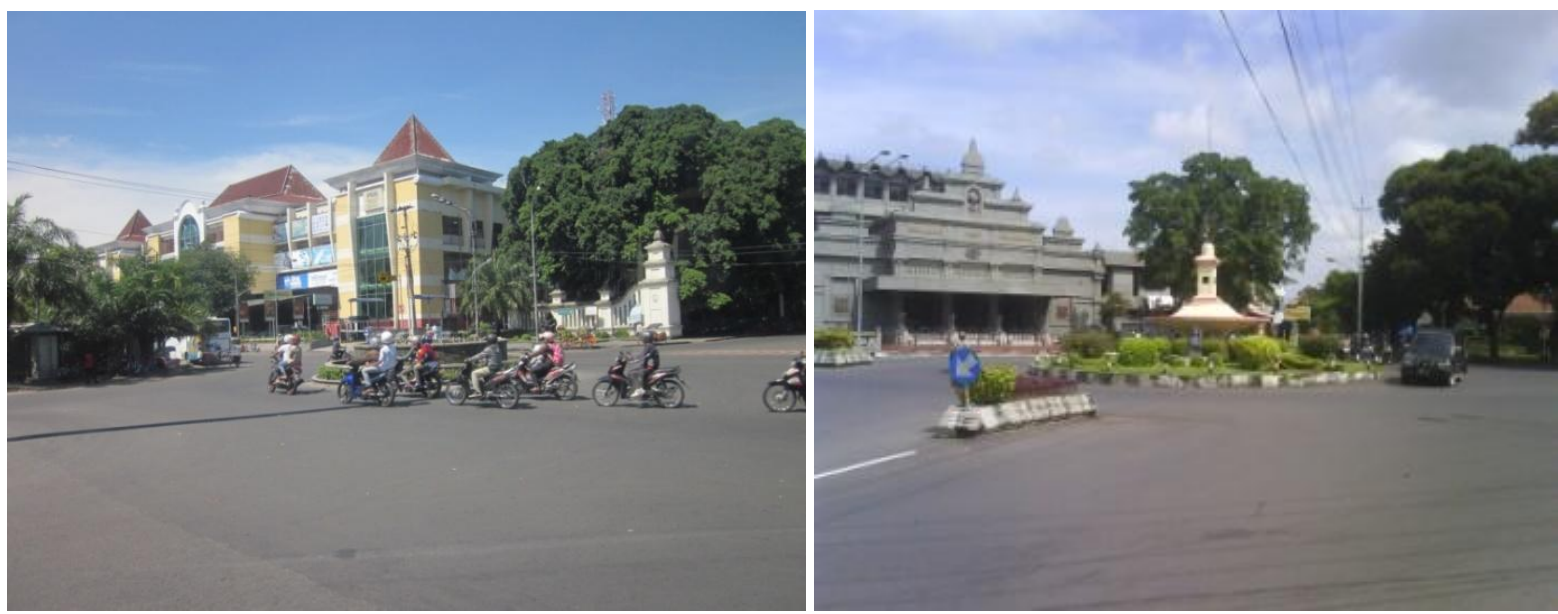
Gambar 5: Persimpangan Gladag (kiri) dan Persimpangan Monumen Pers (kanan). Perlu pembuatan pulau-pulau untuk mengatur jalur kendaraan dan perlindungan terhadap pejalan kaki. Perlu dihindari penanaman pohon, taman yang mengganggu pandangan pengguna jalan. Pengadan jalur pejalan kaki bisa dengan kapasitas besar.

\subsection{Fungsi estetika}

Estetika di persimpangan jalan bisa diwujudkan dengan keberadaan bangunan sudut yang indah dan megah. Keindahan itu akan berkurang bila terdapat papan iklan yang tidak selaras dengan keadaan lingkungan sekitarnya. Pembuatan detail-detail dan penyelesaian setiap bagian jalan dan bangunan sangat mempengaruhi keindahan bagian kota ini. Keindahan akan bertambah bila elemen-elemen jalan dan jalur sirkulasi berfungsi dengan baik. Kawasan Ngarsopuro adalah kawasan citywalk dengan karakter campuran colonial-tradisional-modern. Keindahan kawasan ini sudah terlihat dari persimpangan, dimana bangunan sudut yang bergaya colonial berdampingan dengan shelter modern, dan diikuti dengan elemen street furniture yang bergaya tradisional. (Gambar 6)

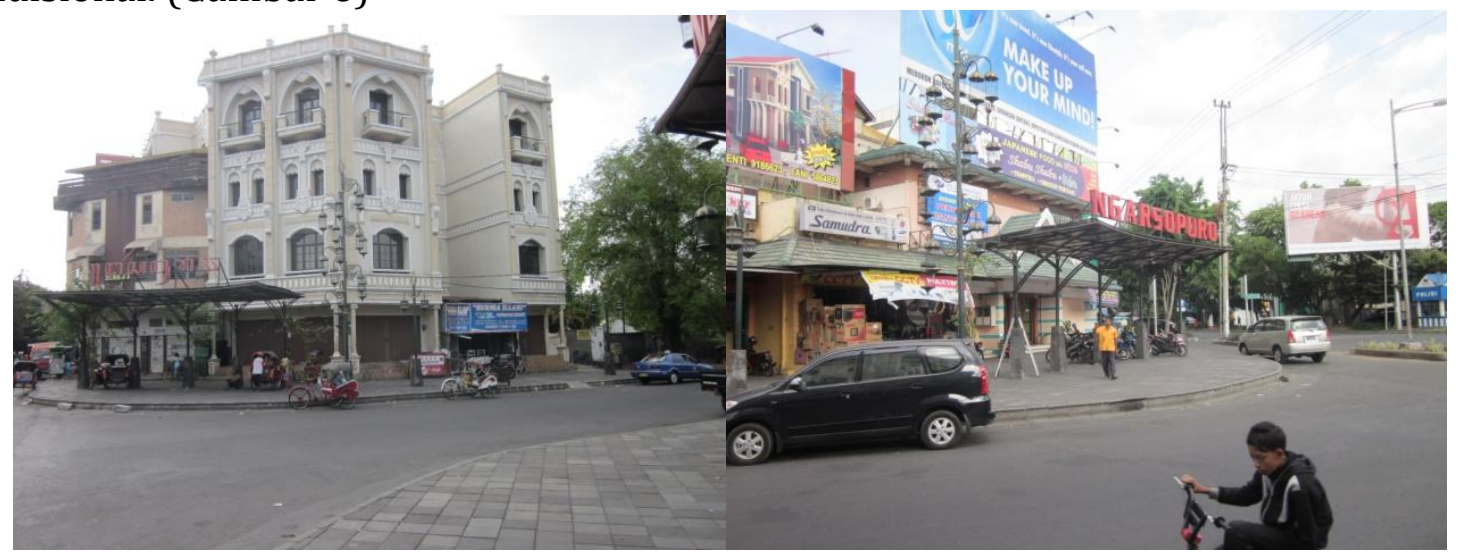

Gambar 6: Persimpangan Ngarsopuro, sudut Utara-Barat (kiri) dan sudut Utara-Timur (kanan) dengan karakter campuran "kolonial-tradisional-modern".

\subsection{Fungsi sosial-budaya;}

Untuk persimpangan yang besar memungkinkan berfungsi sebagai plaza, tempat untuk berkumpul, berdemo dan pemajangan patung sculpture, air mancur dan karya seni lainnya. Persimpangan di Solobaru didesain untuk fungsi semacam itu. Fungsi itu akan optimal pada saat CFD Minggu pagi, dimana banyak masyarakat berkumpul untuk berinteraksi social dan menikmati keindahan karya seni tersebut. (Gambar 7) Untuk persimpangan kecil memungkinkan sebagai tempat berkumpul untuk event tertentu dengan melarang kendaraan masuk. 


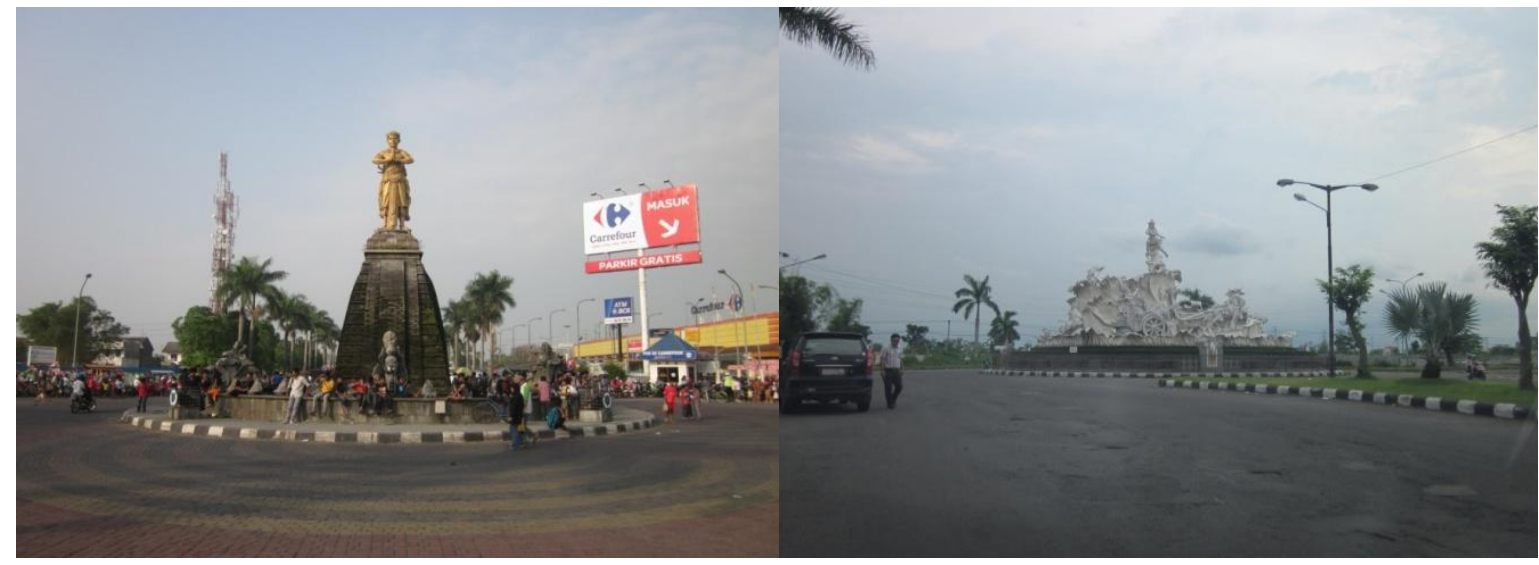

Gambar 7: Persimpangan Pandawa (kiri) dan Persimpangan Dewaruci (kanan) di Solobaru Fungsi sosial- budaya plaza; kecenderungan sebagai tempat berkumpul dan rekreasi

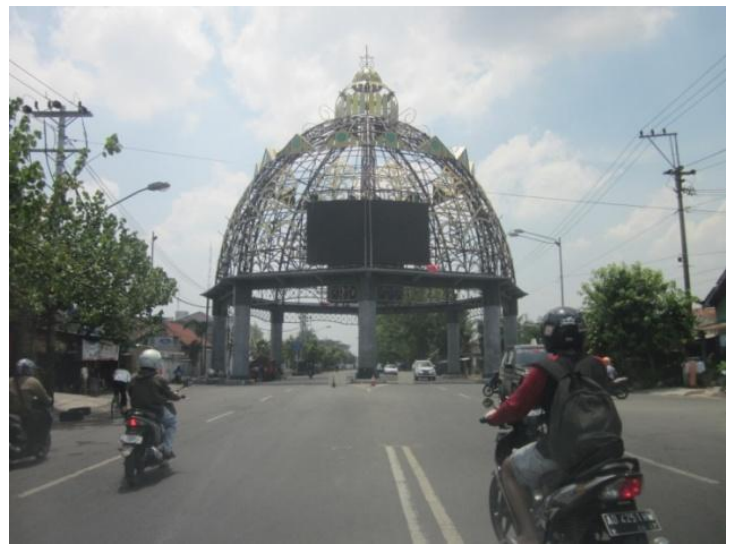

Gambar 8: Persimpangan Gapura

Makutho Solo. Contoh titik strategis sebagai pintu gerbang kota.

Memungkinkan fungsi social-budaya dan ekonomi diakomodasi.

\subsection{Fungsi ekonomi}

Persimpangan jalan mempunyai nilai strategis yang sangat tepat untuk pemasangan iklan outdoor. Pkl akan selalu mencari kesempatan untuk bisa berjualan di kawasan ini. Bahkan pemilik toko di sudut akan memajang dagangannya sampai keluar. Pemerintah kotapun akan "menjual"ititik trategis ini dengan mahal. Hampir tidak ada persimpangan jalan di Surakarta tanpa space iklan. Kekacauan visual yang disebabkan oleh potensi ekonomi dari masyarakat periklanan yang tidak dikelola dengan baik akan merusak estetika kota.

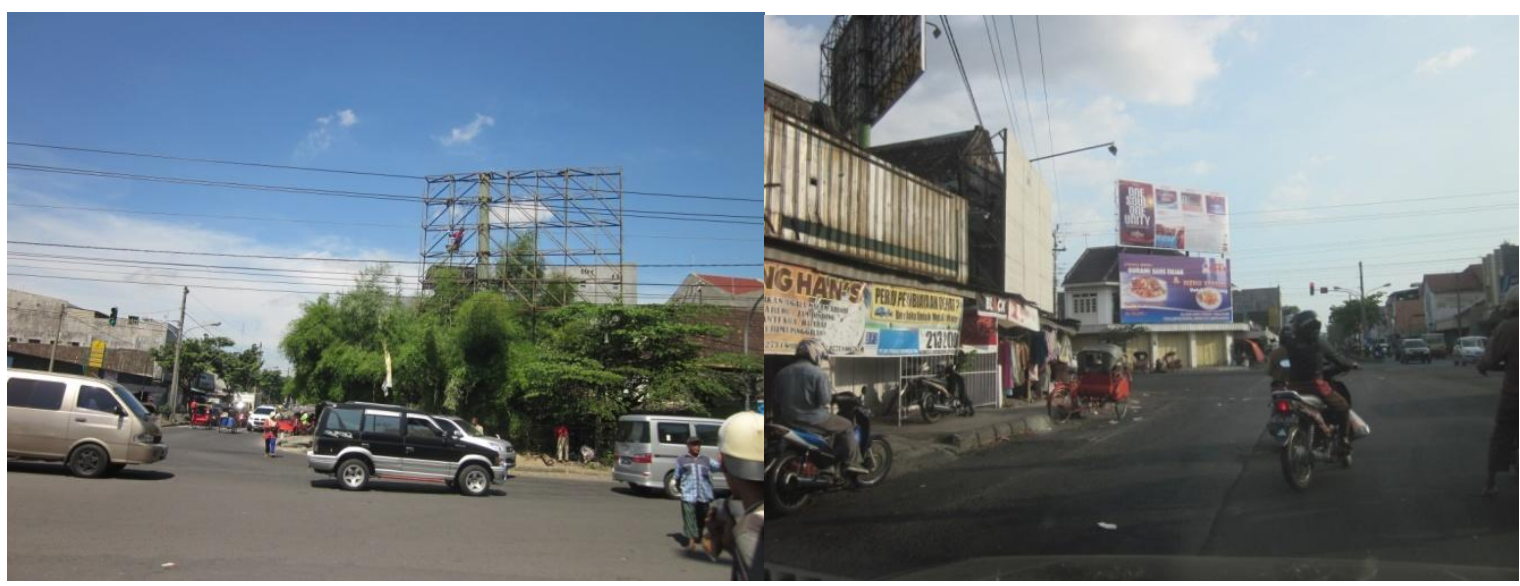


Gambar 9: Persimpangan Gemblegan. Konstruksi papan iklan untuk menutupi bangunan sudut yang jelek. Konstruksi yang tidak kokoh bisa membahayakan pengguna jalan.

\subsection{Pengelolaan berbasis masyarakat}

Hampir semua persimpangan yang diamati memerlukan penataan/desain geometri jalan sesuai dengan standard dan karakteristik kendaraan maupun pengguna disetiap daerah persimpangan. Perlu pengaturan yang jelas dan tegas untuk fungsi utama penggunaan dan fungsi tambahan agar tidak ada pelanggaran yang disebabkan oleh kurangnya pemahaman masyarakat.

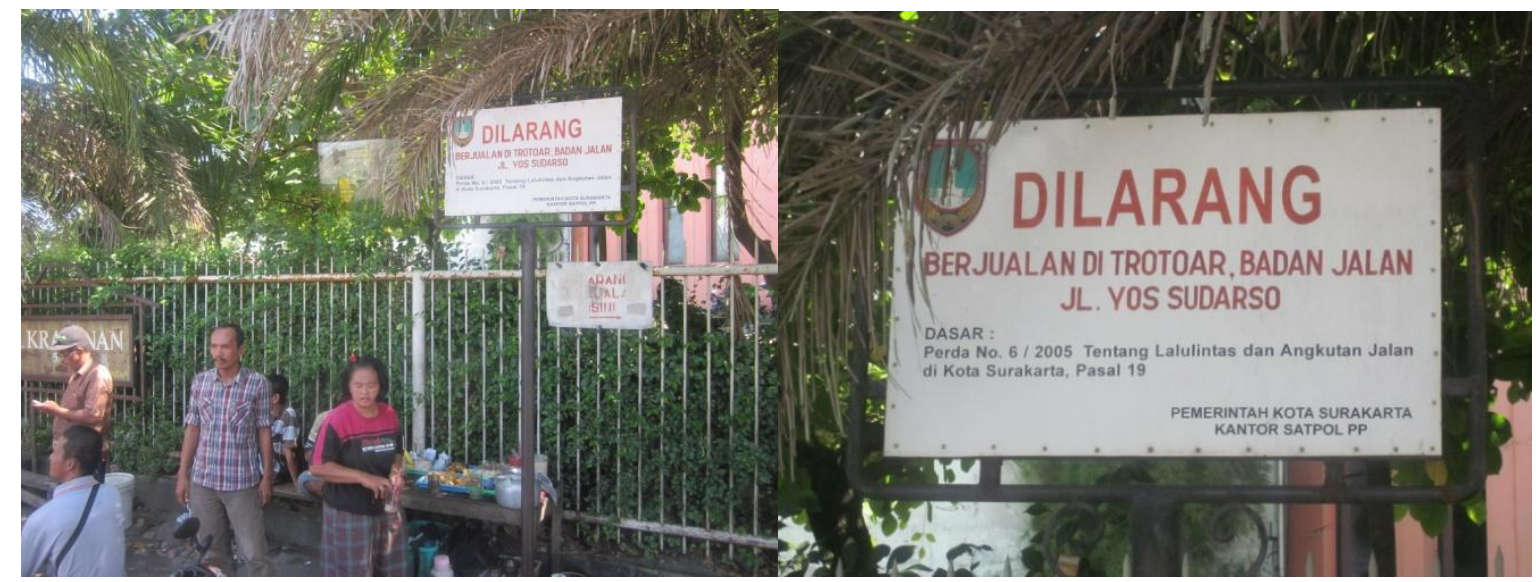

Gambar 10: Aktifitas PKL yang mengabaikan larangan berjualan di trotoar di Persimpangan Gemblegan

Perlu kesadaran masyarakat untuk tidak beraktifitas yang dapat mengganggu kelancaran dan keamanan lalulintas kendaraan dan pejalan kaki. Aktifitas yang diperbolehkan perlu dibicarakan dan disepakati bersama. Wakil-wakil dari kelompok masyarakat yang terkait dan interest pada setiap kasus ruang public di persimpangan perlu diajak membicarakan bagaimana persimpangan itu ditata dan dikelola, agar fungsi utama, sebagai sarana lalu-lintas, fungsi estetika, fungsi social-budaya dan ekonomi bisa bekerja dengan baik.

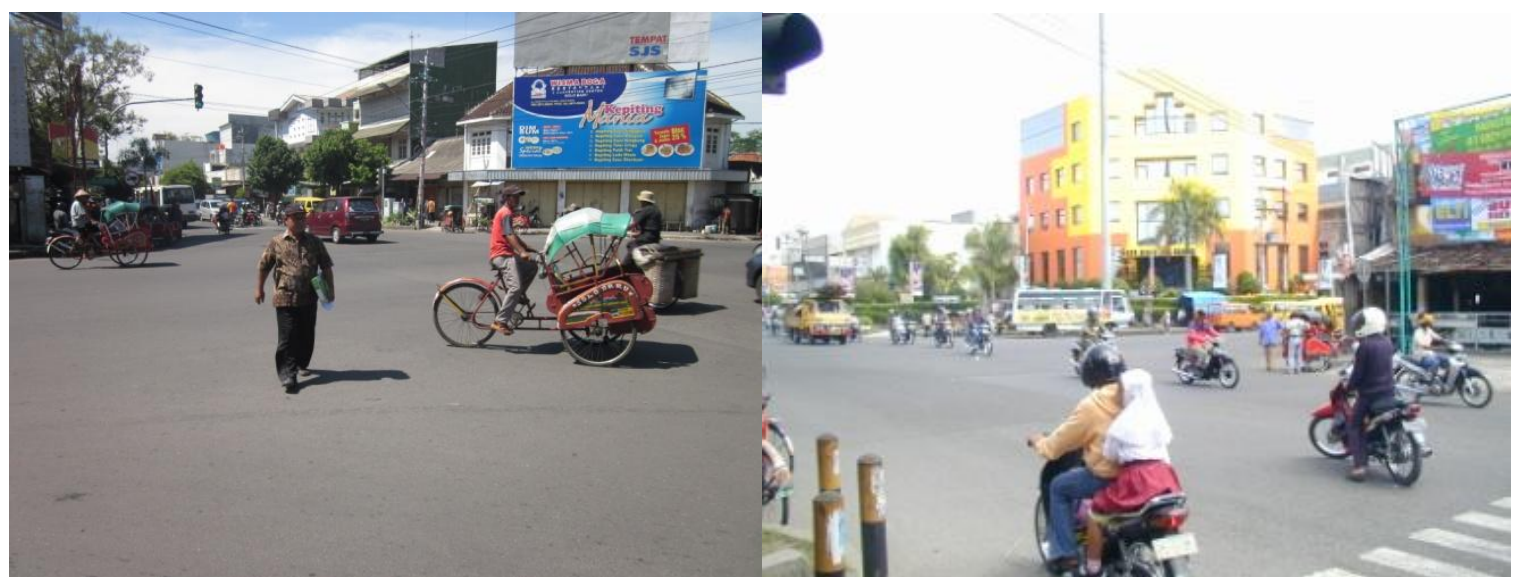

Gambar 11: Persimpangan Gemblegan. Aktifitas menyeberang yang berbahaya, bis kota, becak yang berhenti di sudut jalan menunggu penumpang. 
Pemilik dan pengelola bangunan sudut perlu diajak untuk mendesain bangunannya sebagai unsur utama dalam mewujudkan estetika kota. Disamping itu untuk bangunan sudut di persimpangan yang kecil perlu disesuaikan desainnya sedemikian rupa, sehingga akses pejalan kaki cukup lebar dan sudut pandang pengendara cukup baik. Aktifitas ekonomi di bangunan sudut untuk toko perlu dijaga agar tidak ada penempatan parkir dan barang dagangan yang menghalangi jalur pejalan kaki.
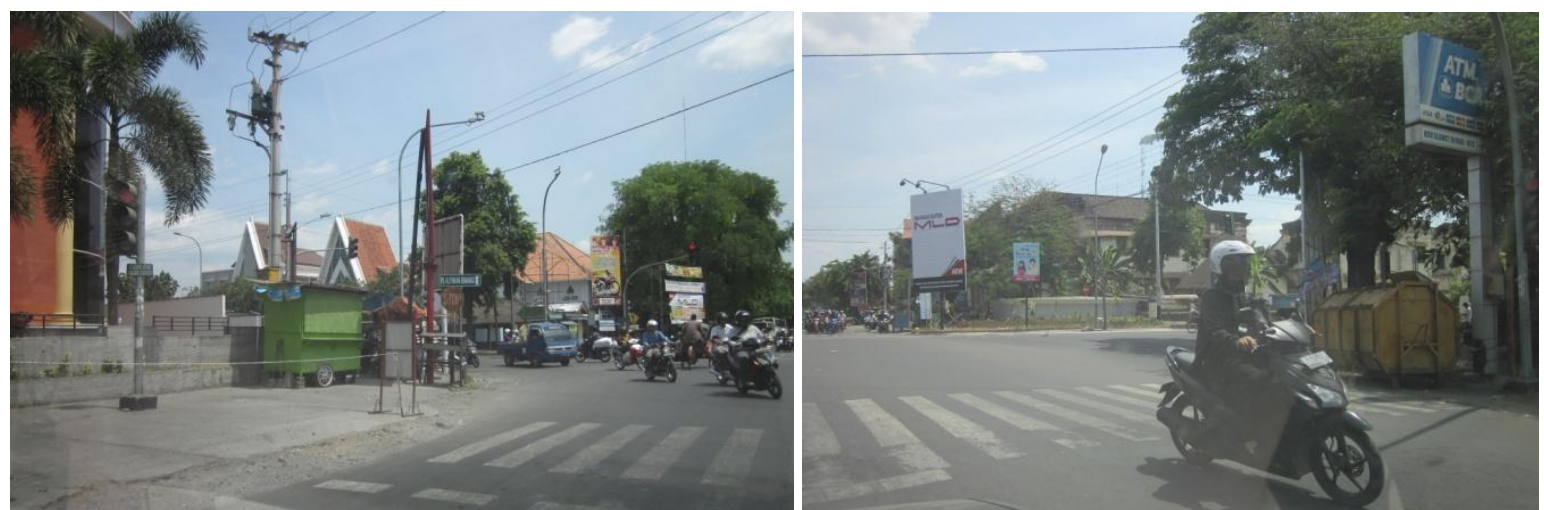

Gambar 12: Persimpangan Sangkrah. Pemerintah kota menunggu sampai proyek penataan persimpangan ini dimulai, dan membiarkan aktifitas yang mengganggu seperti PKL dan bahkan bak truk sampahpun ditaruh di sudut jalan.

Penghargaan Adipura adalah salah satu bentuk stimulan terhadap pengelolaan kota, yang cukup efektif, khususnya untuk pengelolaan persimpangan jalan. Kota-kota yang mendapat Adipura sangat terlihat persimpangan jalan tertib dan indah. Persimpangan jalan yang kacau secara visual maupun lalu-litasnya menunjukkan pengelolaan kota yang masih belum baik. Fungsi social dan ekonominya barangkali sudah tercapai, tapi fungsi lalulintas dan estetikanya belum.

Urban design review adalah pengelolaan proses desain lingkungan kota yang mampu mengarahkan desain kota yang bisa mengakomodasi berbagai interest dan keinginan masyarakat di beberapa kota besar di dunia. Konsep ini bisa juga dipakai sebagi bentuk pengelolaan persimpangan dalam kota melalui pendekatan desain urban.

\section{Kesimpulan}

Pengaturan dan pengelolaan ruang publik di persimpangan dengan berbasis masyarakat memerlukan pemahaman bersama bahwa persimpangan jalan memiliki fungsi utama sebagai sarana lalulintas kendaraan dan orang/pejalan kaki. Selain itu persimpangan jalan memiliki fungsi estetika, fungsi social-budaya dan fungsi ekonomi. Persimpangan jalan bisa dikelompokkan dalam persimpangan besar dan persimpangan kecil.

Untuk persimpangan besar, diperlukan pembuatan marka dan pulau-pulau untuk mengatur jalur kendaraan dan perlindungan terhadap pejalan kaki. Perlu menghindari penanaman pohon, taman yang mengganggu pandangan pengguna jalan. Pengadaan jalur untuk pejalan kaki bisa dengan lebih leluasa dan dengan kapasitas besar. Penanganan estetika untuk bangunan sudut kemungkinannya menjadi lebih megah, jarak pandang cukup. Fungsi social-budaya dan ekonomi lebih besar. Memungkinkan berfungsi sebagai plaza, dan pemajangan patung/karya seni. Cukup 
luas space untuk pemasangan iklan outdoor, dengan mengoptimalkan keberadaan dan kondisi bangunan sudut, untuk menjaga keindahan arsitekturnya.

Untuk persimpangan kecil, fungsi lalulintas perlu pengelolaan secara optimal sebagai jalur sirkulasi kendaraan dan orang. Penanganan estetika bangunan sudut memungkinkan dengan detail-detil dan tekstur yang bisa diamati dari dekat. Penyediaan ruang bebas pandang dan sirkulasi kendaraan dan pejalan kaki perlu dilakukan dengan mendesain ulang bagian bangunan sudut. Pemilik bangunan sudut memiliki kewajiban untuk mendukung usaha itu. Keberadaan tugu di tengah perempatan kurang sesuai untuk mengatur jalur kendaraan. Kendaraan besar seperti bus, sulit berbelok. Fungsi ekonomi memungkinkan diwujudkan dengan pemasangan iklan outdoor secara terbatas, desesuaikan dengan keberadaan bangunan sudut.

Rangsangan penghargaan prestise semacam Adipura, dengan kriteria penilaian yang lebih tinggi untuk keindahan dan ketertiban di persimpangan jalan, akan memacu usaha pengelolaan ruang public di persimpangan dengan melibatkan semua elemen dalam masyarakat kota, terutama pemerintah kota. Keberadaan tim review design urban akan membantu proses mewujudkan ruang public di persimpangan yang indah, tertib, manusiawi dan berkeadilan.

\section{Daftar Pustaka}

Alexander, C., Ishikawa, S., Silverstein, M. 1977. A Pattern Language. New York: Oxford University Press

Lynch, Kevin. 1976. Managing the Sence of a Region. Cambridge: The MIT Press. Marpaung, Beny Oktofryana Yousca. 2003. Pola Persimpangan. USU digital library. Ma'soem, Dadang Mohamad, 2007," Persimpangan Jalan yang berada pada Persimpangan Jalan", Pusat Penelitian Jalan dan Jembatan Kemen PU, www.findtoyou.co.id

Shirvani, Hamid. 1981. Urban Design Review: A Guide for Planners, Chicago: the American Planning Association

Thomas, Derek. 2002. Architecture and theUrban Environment: A Vision for the New Age. Cape Town: Architectural Press

en.wikipedia.org/wiki/Selamat_Datang_Monument

http://id.wikipedia.org/wiki/Adipura

https://uripsantoso.wordpress.com/2008/04/03/teknik-penulisan-adipura/ 